\title{
Electrocardiographic Change
}

National Cancer Institute

\section{Source}

National Cancer Institute. Electrocardiographic Change. NCI Thesaurus. Code C50543.

An electrocardiographic finding of a change in cardiac electrical activity. 